\title{
The Predictive Value of left atrial appendage peak flow velocity in Recurrence after initial radiofrequency catheter ablation of persistent atrial fibrillation: A single-center prospective study.
}

Wentao Yang ${ }^{1}$, Qing Zhao ${ }^{2}$, Minghui $\mathrm{Yao}^{3}$, Xiangdong $\mathrm{Li}^{2}$, Yue Zhang ${ }^{2}$, Chuanbin Liu $^{2}$, Zhaoliang Shan ${ }^{2}$, and Yutang Wang ${ }^{1}$

${ }^{1}$ Nankai University

${ }^{2}$ Chinese PLA General Hospital

${ }^{3}$ Sixth Medical Center of PLA General Hospital

June 19, 2021

\begin{abstract}
Background: Recurrence after Radiofrequency catheter ablation(RFCA) of persistent atrial fibrillation (PeAF) is still elusive. The present study aimed to evaluate the relationship between the left atrial appendage peak flow velocity(LAAV) and atrial fibrillation(AF) recurrences in PeAF patients after their initial RFCA. Method: This study included 164 consecutive PeAF patients who performed initial RFCA from January 2018 to December 2019. Transesophageal echocardiography was used to collect the LAAV before ablation. Patients' demographic and clinical information was gathered. To detect the recurrences of $\mathrm{AF}$, patients were checked up at routine intervals. A Cox proportional hazards regression analysis was adopted to evaluate the LAAV and other clinical variables as predictors of AF recurrences throughout follow-up. Results: AF recurrence resulted in 43 (26.2\%) patients after a median follow-up of 15 months (IQR: 12-18 months). LAAV reduced in patients with AF recurrences $(0.36 \pm 0.15 \mathrm{~m} / \mathrm{s}$ vs. $0.45 \pm 0.17 \mathrm{~m} / \mathrm{s}, \mathrm{P}=0.004)$. A Kaplan-Meier study revealed that the low LAAV $([?] 0.37 \mathrm{~m} / \mathrm{s}) \operatorname{group}$ had a lower event-free survival rate than the high LAAV $(>0.37 \mathrm{~m} / \mathrm{s})$ group $(17.6$ months vs. 21.2 months, Log Rank $\mathrm{P}=0.002)$. LAAV[?]0.37m/s (HR 2.32, 95\% CI 1.177-4.227, P = 0.014) was found to be independent predictors of AF recurrence after RFCA in the multivariate Cox regression. Conclusion: A low LAAV is linked to AF recurrence and acts as a predictor of AF recurrence after the initial RFCA of peAF. This would aid in treatment strategy optimization and management of patients with peAF.
\end{abstract}

\section{Hosted file}

The Predictive Value of LAAV in Recurrence after \selectlanguage\{ngerman\} initial catheter ablation of available at https: //authorea.com/users/420632/articles/526940-the-predictive-value-of-leftatrial-appendage-peak-flow-velocity-in-recurrence-after-initial-radiofrequency-catheterablation-of-persistent-atrial-fibrillation-a-single-center-prospective-study

\section{Hosted file}

Table 1.docx available at https://authorea.com/users/420632/articles/526940-the-predictivevalue-of-left-atrial-appendage-peak-flow-velocity-in-recurrence-after-initialradiofrequency-catheter-ablation-of-persistent-atrial-fibrillation-a-single-centerprospective-study

\section{Hosted file}


Table 2.docx available at https://authorea.com/users/420632/articles/526940-the-predictivevalue-of-left-atrial-appendage-peak-flow-velocity-in-recurrence-after-initialradiofrequency-catheter-ablation-of-persistent-atrial-fibrillation-a-single-centerprospective-study

\section{Hosted file}

Table 3.docx available at https://authorea.com/users/420632/articles/526940-the-predictivevalue-of-left-atrial-appendage-peak-flow-velocity-in-recurrence-after-initialradiofrequency-catheter-ablation-of-persistent-atrial-fibrillation-a-single-centerprospective-study

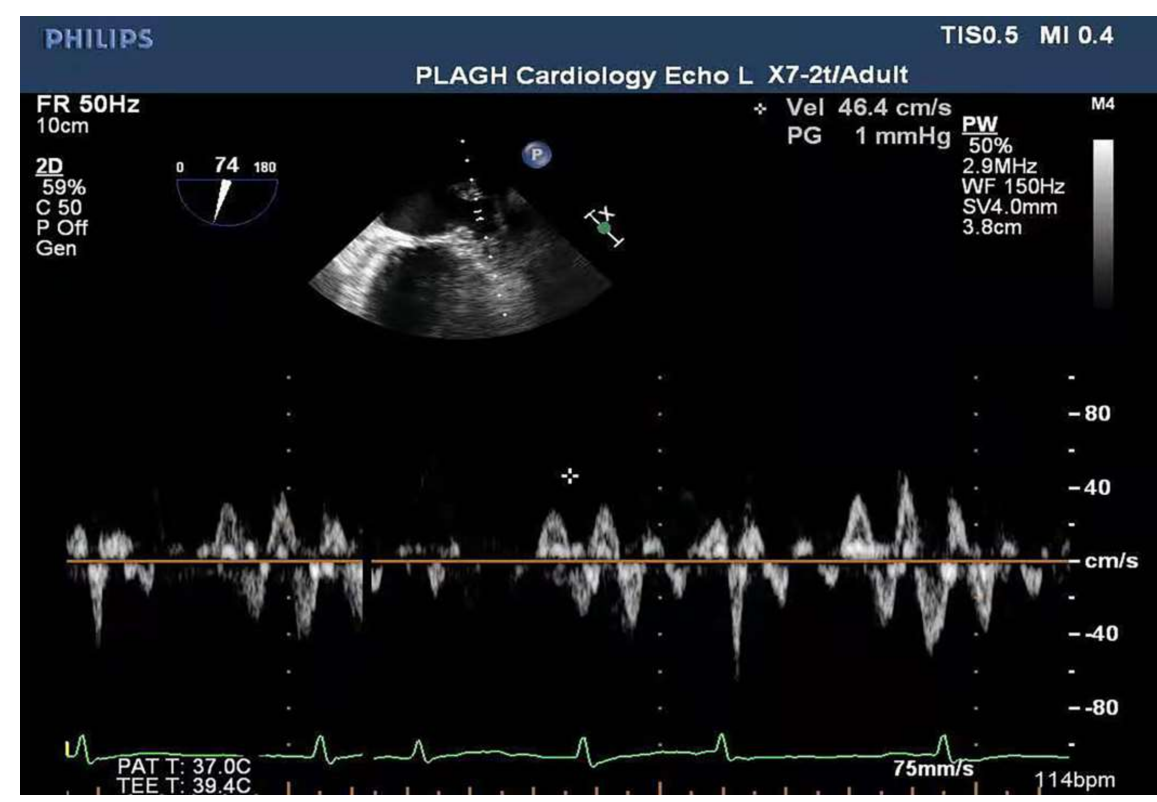



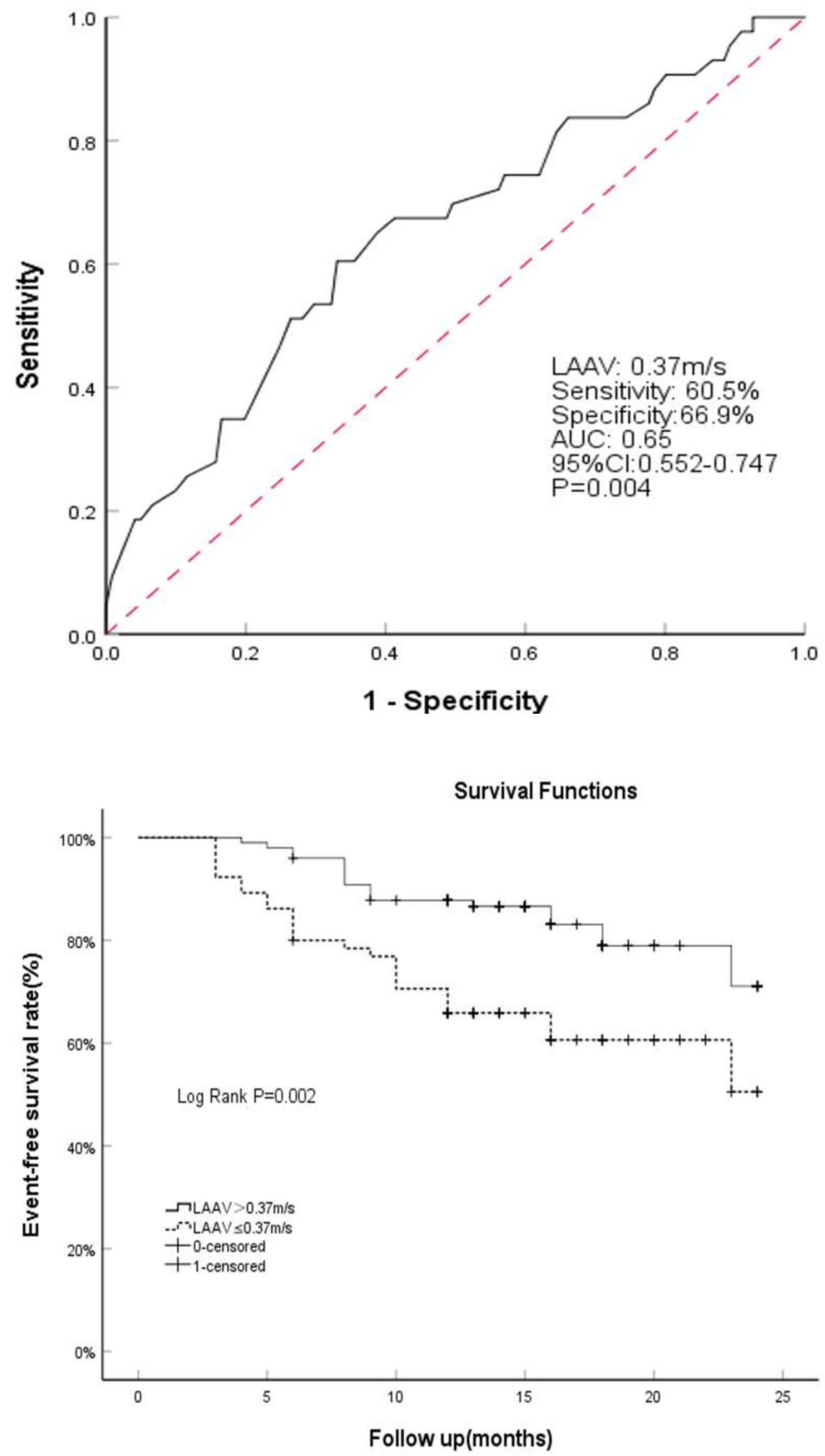